\title{
Processing and Characterization of Glass-epoxy Composites Filled with Linz-donawitz (LD) Slag
}

\author{
Pravat Ranjan Pati*, Alok Satapathy \\ Department of Mechanical Engineering, National Institute of Technology, Rourkela, India
}

Copyright $@ 2015$ Horizon Research Publishing All rights reserved.

\begin{abstract}
Linz-Donawitz (LD) slag a major solid waste generated in huge quantities during steel making. It comes from slag formers such as burned lime/dolomite and from oxidizing of silica, iron etc. while refining the iron into steel in the LD furnace. Although a number of ways for its utilization have been suggested, its potential as a filler material in polymeric matrices has not yet been explored. The present work reports the possible use of this waste in glass fiber reinforced epoxy composites as a filler material. Hybrid composites consisting of bi-directional E-glass-fiber reinforced epoxy filled with different LD slag content $(0,7.5$, $15,22.5 \mathrm{wt} \%$ ) are prepared by simple hand lay-up technique. The composites are characterized in regard to their density, porosity, micro-hardness and strength properties. X-ray diffractography is carried out in order to ascertain the various phases present in LDS. This work shows that LD slag, in spite of being a waste, possesses fairly good filler characteristics as it modifies the strength properties and improves the composite micro-hardness of the polymeric resin.
\end{abstract}

Keywords Characterization, Glass-epoxy Composites, LD Slag, Waste Utilization

\section{Introduction}

Fiber reinforced polymer (FRP) composites have various applications in automobile, aerospace and marine. FRP composites are applied to inlet cone, fan exit-guide vanes and other parts of structures in a turbofan engine for lightening an engine. These composites have generated wide interest in various engineering fields including tribological applications such as cams, clutches, brakes, bearings, wheels, rollers, seals and gears due to their good combination of high specific strength, high modulus, low density and better wear resistance [1]. Being light weight they are the most suitable materials for weight sensitive uses, but their high cost sometimes becomes the limiting factor for commercial applications. Use of low cost, easily available fillers is therefore useful to bring down the cost of composites. Available references suggest a large number of materials being used as fillers in polymers [2-4]. Various kinds of polymers and polymer matrix composites reinforced with metal particles have a wide range of industrial applications such as heaters, electrodes [5], composites with thermal durability at high temperature [6] etc. Hard particulate fillers consisting of ceramic or metal particles and fiber-fillers made of glass are being used these days to improve the performance of polymer composites to a great extent [7]. The inclusion of such particulate fillers into polymers for commercial applications is primarily focused at the cost reduction and stiffness improvement [8]. Various researchers [9-12] have reported that the wear resistance of polymers is improved by the addition of fillers. There have been various reports on the use of inorganic fillers like alumina and silica in polypropylene [13, 14] and polyethylene $[15,16]$. But in this context, the potential of industrial wastes for such use in polymeric matrices has rarely been explored. Rapid industrial development over the last decades has led to the generation of large amounts of solid wastes in the form of ash, mud or slag, which has now come to a stage for environmental threat and needs disposal and/or utilization. Most of these wastes are buried in landfills, which is costly and environmentally unsatisfactory. Therefore, it is essential to seek new options to recycle or reuse these inorganic residues. It is evident from the characteristics of some of these wastes, generated from different processes, that they have good potential for recycling and for utilization in developing various value-added products. Against this background, an attempt has been made in this research work to effectively utilize an industrial waste like LD slag as the particulate filler for making composite materials.

\section{Experimental Details}

\subsection{Material}

LD slag collected from Rourkela Steel Plant, located in the 
eastern part of India is used as the filler material in this investigation. These slag particles are sieved to obtain an average particle size in the range of $90-100 \mu \mathrm{m}$. The major constituents of the LDS (density about $1.75 \mathrm{~g} / \mathrm{cm}^{3}$ ) used are silicon oxide, calcium oxide and iron oxide.

\subsection{Composite Fabrication}

E-glass fibers (360 roving taken from Saint Gobian Ltd.) are reinforced in LD slag filled epoxy, chemically belonging to the 'epoxide' family is used as the matrix material. Its common name is bisphenol-A-diglycidyl-ether. This low temperature curing epoxy resin (LY 556) and corresponding hardener (HY951) are mixed in a ratio of 10:1 by weight as recommended. The epoxy resin and the hardener are supplied by Ciba Geigy India Ltd. E-glass fiber and epoxy resin have modulus of $72.5 \mathrm{GPa}$ and $3.42 \mathrm{GPa}$, respectively and possess density of $2.59 \mathrm{~g} / \mathrm{cm}^{3}$ and $1.1 \mathrm{~g} / \mathrm{cm}^{3}$ respectively. Composites of four different compositions $(0$, $7.5,15$ and $22.5 \mathrm{wt} \%$ LD slag filling) are made and the fiber loading (weight fraction of glass fiber in the composite) is kept at $50 \%$ for all the samples. The castings are put under load for about 24 hours for proper curing at room temperature. The composites are cast in these molds so as to get rectangular slabs. From these slabs the specimens of required dimensions are cut for different characterization tests.

\subsection{Density and Void Fraction}

The theoretical density of composite materials in terms of weight fraction can easily be obtained as for the following equations given by Agarwal and Broutman [17].

$$
\rho_{c t}=\frac{1}{\left(W_{f} / \rho_{f}\right)+\left(W_{m} / \rho_{m}\right)}
$$

Where, $W$ and $\rho$ represent the weight fraction and density, respectively. The suffix $f, m$ and $c t$ stand for the fiber, matrix and the composite materials, respectively.

The composites under this investigation consists of three components namely matrix, fiber and particulate filler. Hence the modified form of the expression for the density of the composite can be written as

$$
\rho_{c t}=\frac{1}{\left(W_{f} / \rho_{f}\right)+\left(W_{m} / \rho_{m}\right)+\left(W_{p} / \rho_{p}\right)}
$$

Where, the suffix ' $p$ ' indicates the particulate filler materials.

The actual density $\left(\rho_{c e}\right)$ of the composite, however, can be determined experimentally by simple water immersion technique. The volume fraction of voids $\left(V_{v}\right)$ in the composites is calculated using the following equation.

$$
V_{v}=\frac{\rho_{c t}-\rho_{c e}}{\rho_{c t}}
$$

\subsection{Micro-hardness}

Micro-hardness measurement is done using a Leitz micro-hardness tester. A diamond indenter, in the form of a right pyramid with a square base and an angle $136^{\circ}$ between opposite faces, is forced into the material under a load F. The two diagonals $\mathrm{X}$ and $\mathrm{Y}$ of the indentation left on the surface of the material after removal of the load are measured and their arithmetic mean L is calculated. In the present study, the load considered $F=0.5 \mathrm{~N}$ and Vickers hardness number is calculated using the following equation.

$$
H_{v}=0.1889 \frac{F}{L^{2}} \text { and } L=\frac{X+Y}{2}
$$

Where, $F$ is the applied load (N), $L$ is the diagonal of square impression (mm), $X$ is the horizontal length $(\mathrm{mm})$ and $Y$ is the vertical length $(\mathrm{mm})$.

\subsection{Tensile Strength}

The tensile test is generally performed on flat specimens. The commonly used specimen for tensile test is the dog-bone specimen and straight side specimen with end tabs. A uniaxial load is applied through both the ends. The ASTM standard test method for tensile properties of composites has the designation D 3039-76. The tensile test is performed in the universal testing machine (UTM) Instron 1195 at a crosshead speed of $10 \mathrm{~mm} / \mathrm{min}$ and results are analyzed to calculate the tensile strength of composite samples.

\subsection{Flexural Strength}

The flexural strength of a composite is the maximum tensile stress that it can withstand during bending before reaching the breaking point. The standard three point bend test as per ASTM D5379/D5379M is conducted on all the composite samples using the same universal testing machine. Span length of $40 \mathrm{~mm}$ and a crosshead speed of $10 \mathrm{~mm} / \mathrm{min}$ are maintained. The flexural strength $(F . S)$ of the composite specimens is determined using the following equation.

$$
F \cdot S=\frac{3 P l}{2 b t^{2}}
$$

Where, $l$ is the span length of the sample, $P$ is the load applied, $b$ and $t$ are the width and thickness of the specimen respectively.

\subsection{Impact Strength}

The pendulum impact testing machine confirming to ASTM D 256 ascertains the notch impact strength of the material by shattering the specimen with a pendulum hammer, measuring the spent energy and relating it to the cross-section of the specimen. The machine is adjusted such that the blade on the free-hanging pendulum just barely contracts the specimen (zero position). The specimens are clamped in a square support and are struck at their central point by a hemispherical bolt of diameter $5 \mathrm{~mm}$. The respective values of impact energy of different specimens are recorded directly from the dial indicator. 
Table 1. Measured and theoretical densities of the composites

\begin{tabular}{ccccc}
\hline Sample no. & $\begin{array}{c}\text { Filler content } \\
(\mathrm{wt} \%)\end{array}$ & $\begin{array}{c}\text { Theoretical density } \\
\left(\mathrm{g} / \mathrm{cm}^{3}\right)\end{array}$ & $\begin{array}{c}\text { Measured density } \\
\left(\mathrm{g} / \mathrm{cm}^{3}\right)\end{array}$ & $\begin{array}{c}\text { Void fraction } \\
(\%)\end{array}$ \\
\hline 1 & 0 & 1.242 & 1.226 & 1.288 \\
2 & 7.5 & 1.319 & 1.294 & 1.895 \\
3 & 15 & 1.412 & 1.372 & 2.832 \\
4 & 22.5 & 1.531 & 1.475 & 3.657 \\
\hline
\end{tabular}

\section{Results and Discussion}

\subsection{Density and Porosity Analysis}

In the present research work, the measured densities and volume fraction of voids (porosities) of LD slag filled glass-epoxy composites are presented in Table 1 . It is observed that, by the addition of LD slag particles the density of the composites is gradually increases. It also noted that, the increment in the $\mathrm{wt} \%$ of filler in the matrix leads to increase in porosity.

\subsection{Micro-hardness Analysis}

The variations in the hardness values of the composites with filler content are shown in Fig. 1. Hardness is considered as one of the most important factors that govern the wear resistance of any material. In the present work, micro-hardness values of the composites with the fillers in different proportions have been obtained. It is observed that the hardness of the composites increases with increase in filler content. The micro-hardness values recorded in Vickers' scale for the composites are 24.98, 26.31, 29.26 and $32.83 \mathrm{Hv}$ respectively.

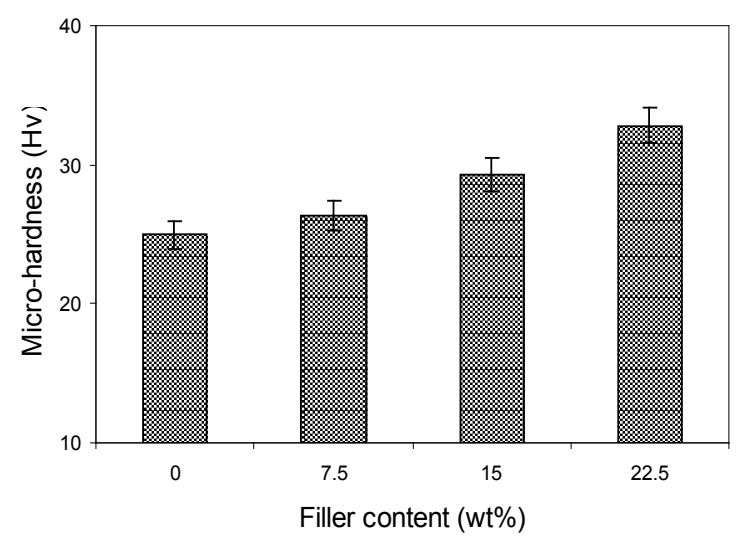

Figure 1. Variation of micro-hardness with filler content

\subsection{Tensile Strength Analysis}

The tensile strengths of the composites with different filler content are shown in Fig. 2. It is seen that in all the samples the tensile strength of the composites decreases with increase in filler content. The composite with $0 \mathrm{wt} \%$ of $\mathrm{LD}$ slag has strength of $245.54 \mathrm{MPa}$ in tension and it is noticed that this value drops to $221.43 \mathrm{MPa}$ with inclusion of $7.5 \mathrm{wt} \%$ of $\mathrm{LD}$ slag. The tensile strength of the sample is further drops to 192.57 MPa and 175.21 MPa in the case of other two composites with 15 and $22.5 \mathrm{wt} \%$ of LD slag respectively. This reduction might be due to the voids present in the composite body and due to stress concentration arising out of the sharp corners of the irregular shaped LD slag particles.

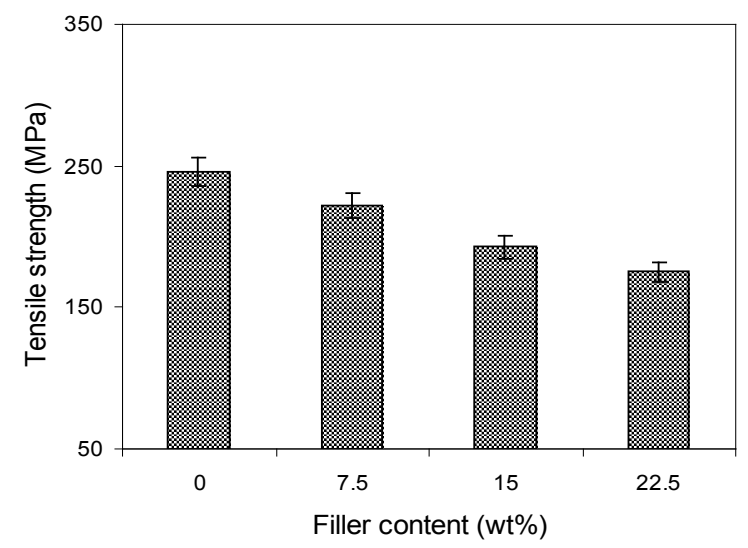

Figure 2. Variation of tensile strength with filler content

\subsection{Flexural Strength Analysis}

Composite materials used in structures are prone to fail in bending and therefore the development of new composites with improved flexural characteristics is essential. In the present work, the variations of flexural strength of glass-epoxy composites with LD slag content are shown in Fig. 3. Marginal decrement in flexural strength with the incorporation of LD slag particles is recorded for all the composite samples.

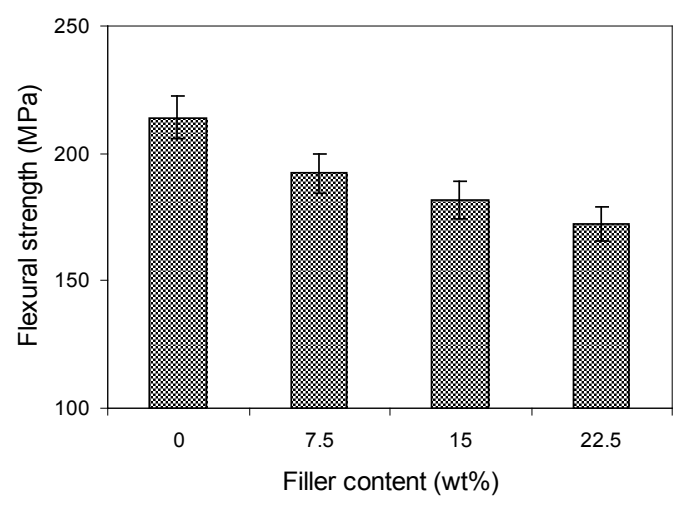

Figure 3. Variation of flexural strength with filler content 


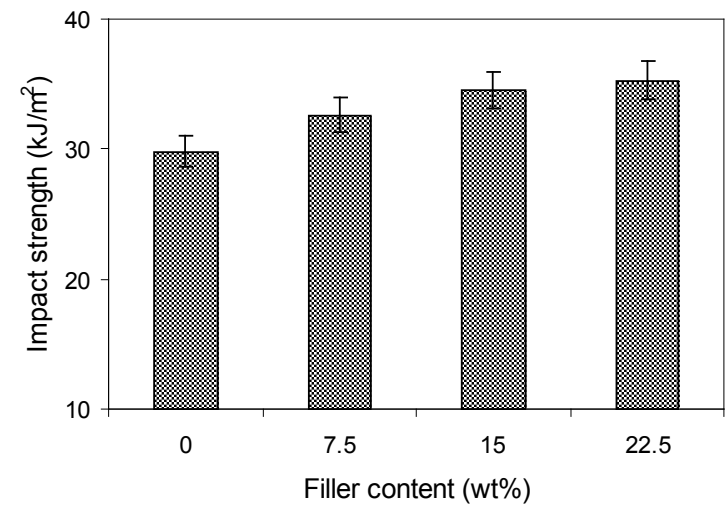

Figure 4. Variation of impact strength with filler content

\subsection{Impact Strength Analysis}

The impact strength of a material is its capacity to absorb and dissipate energies under impact or shock loading. The suitability of a composite for certain applications is determined not only by usual design parameters, but also by its impact or energy absorbing properties. Fig. 4 shows the measured impact energy values of LD slag filled glass-epoxy composites. It is seen that the impact energy of the composite increases gradually with filler content increasing from 7.5 to $30 \mathrm{wt} \%$.

\subsection{X-ray Diffraction (XRD) Studies}

The raw LDS is examined with a Philips $\mathrm{X}$ Ray Diffractometer for the identification of the crystalline phases. The X-ray diffractograms are taken using $\mathrm{Cu} \mathrm{K} \alpha$ radiation. From the diffractogram for raw LDS, shown in Fig.5, it is seen that the major oxide phases present are silica $\left(\mathrm{SiO}_{2}\right)$, lime $(\mathrm{CaO})$ and hematite $\left(\mathrm{Fe}_{2} \mathrm{O}_{3}\right)$

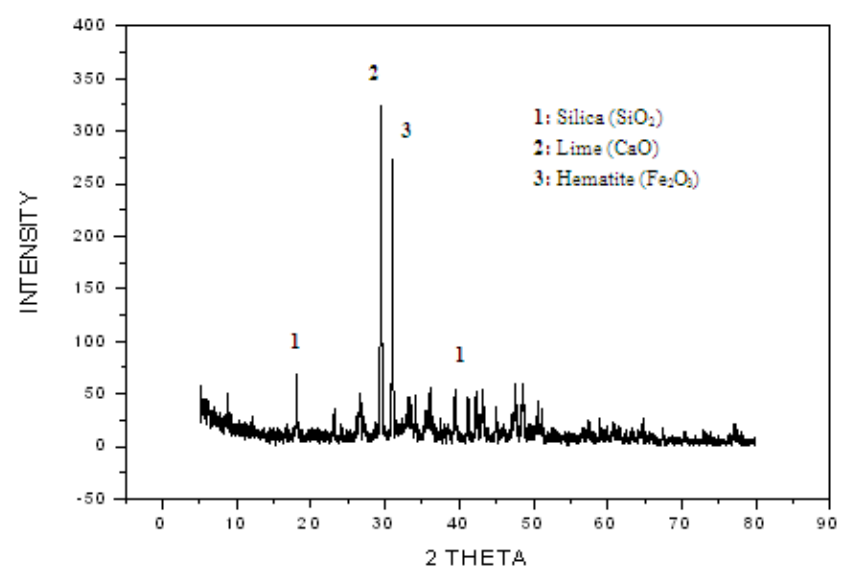

Figure 5. X ray diffractogram of raw LDS.

\section{Conclusions}

Fabrication of hybrid composites consisting of glass-fiber reinforcement in epoxy resin filled with particulate LD slag is possible in simple hand lay-up technique. The hardness and impact strength of these new class hybrid composites are improving with filler addition while a steady decline of tensile and flexural properties are observed. The density of the composites is also greatly influenced by the filler content. This study opens up a new avenue for a value added utilization of an industrial waste like LD slag and can be used as a potential filler material in polymer matrix composites.

\section{REFERENCES}

[1] Hutchings I M. Tribology: friction and wear of engineering materials. London: CRC Press, 1992.

[2] Zhenyu J, Lada A G, Alois K S, Klaus F, Zhong Z. Study on friction and wear behavior of polyphenylene sulfide composites reinforced by short carbon fibers and sub-micro $\mathrm{TiO}_{2}$ particles. Compos Sci Technol, 2008, 68: 734-742.

[3] Chang L, Zhang Z, Breidt C, Friedrich K. Tribological properties of epoxy nanocomposites I. Enhancement of the wear resistance by nano- $\mathrm{TiO}_{2}$ particles. Wear, 2005, 258: 141-148.

[4] Satapathy A, Patnaik A. Analysis of dry sliding wear behaviour of red mud filled polyester composites using the Taguchi method. J Reinf Plast Compos, 2008, 29: 2883-2897.

[5] Jang B Z. Advanced polymer composites: principles and applications. ASM International, 1994.

[6] Jung-il K, Kang $\mathrm{P} H$, Nho Y C. Positive temperature coefficient behaviour of polymer composites having a high melting temperature. J Appl Polym Sci, 2004, 92: 394-401.

[7] Sawyer W G, Freudenberg K D, Praveen B, Schadler L S. A study on the friction and wear behaviour of PTFE filled with alumina nanoparticles. Wear, 2003, 254(5-6): 573-580.

[8] Rothon, R N. Mineral fillers in thermoplastics-filler manufacture and characterization. Adv Polym Sci, 1999, 139: 67-107.

[9] Suresha B, Ramesh B N, Subbaya K M, Ravi Kumar B N, Chandramohan G. Influence of graphite filler on two-body abrasive wear behavior of carbon fabric reinforced epoxy composites. Mater Des, 2010, 31: 1833-1841.

[10] Mohan N, Natarajan S, KumareshBabu S P. Abrasive wear behavior of hard powders filled glass fabric epoxy hybrid composites. Mater Des, 2011, 32: 1704-1709.

[11] Schwartz C J, Bahadur S. The role of filler deformability, filler-polymer bending, and counterface material on the tribological behavior of polyphenylene sulfide. Wear, 2001, 251: 1532-1540.

[12] Xian G, Zhang Z. Effects of the combination of solid lubricants and short carbon fibers on the sliding performance of poly(ether imide) matrix composites. J Appl Polym Sci, 2004, 94: 1428-34.

[13] Mareri P, Bastide S, Binda N, Crespy A. Mechanical Behaviour of Polypropylene Composites Containing Fine Mineral Filler-Effect of Filler Surface Treatment. 
Composites Science and Technology, 1998, 58(6): 747-752.

[14] Jarvela P A, Jarvela P K. Multi-Component Compounding of Polypropylene. Journal of Materials Science, 1996, 31(14): 3853-3859.

[15] Rusu M, Sofian N, Rusu D. Mechanical and Thermal Properties of Zinc Powder Filled High Density Polyethylene Composites. Polymer Testing, 2001, 20(44): 409-417.
[16] Barta S, Bielek J, Dieska P. Study of Thermophysical and Mechanical properties of Particulate Composite Polyethylene-CaCo. Journal of Applied Polymer Science, 1997, 64(8):1525-1530.

[17] Agarwal B D, Broutman L J. Analysis and performance of fiber composites. 2nd edition. John Wiley and Sons, Inc, 1990 . 